This item was submitted to Loughborough's Research Repository by the author.

Items in Figshare are protected by copyright, with all rights reserved, unless otherwise indicated.

\title{
A review of experimental and simulation studies on controlled auto-ignition combustion
}

PLEASE CITE THE PUBLISHED VERSION

http://www.sae.org/events/conferences/

PUBLISHER

(C) SAE International

VERSION

VoR (Version of Record)

LICENCE

CC BY-NC-ND 4.0

REPOSITORY RECORD

Milovanovic, Nesa, and Rui Chen. 2011. "A Review of Experimental and Simulation Studies on Controlled Auto-ignition Combustion”. figshare. https://hdl.handle.net/2134/8401. 
This item was submitted to Loughborough's Institutional Repository (https://dspace.lboro.ac.uk/) by the author and is made available under the following Creative Commons Licence conditions.

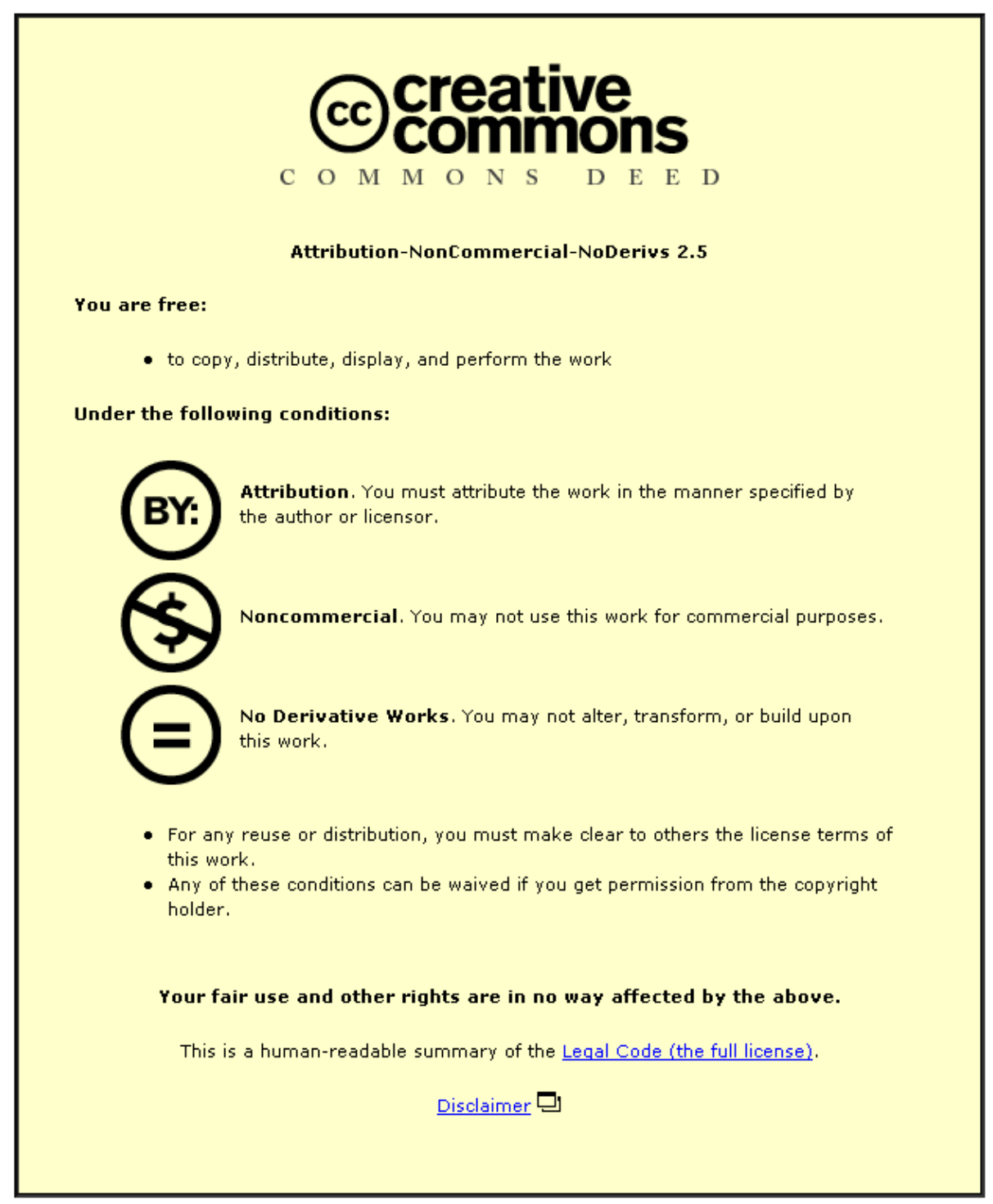

For the full text of this licence, please go to: http://creativecommons.org/licenses/by-nc-nd/2.5/ 


\section{A Review of Experimental and Simulation Studies on Controlled Auto-Ignition Combustion}

Nebojsa Milovanovic and Rui Chen Department of Aeronautical and Automotive Engineering, Loughborough University

Reprinted From: $\mathrm{HCCl}$ Combustion

(SP-1627) 
The appearance of this ISSN code at the bottom of this page indicates SAE's consent that copies of the paper may be made for personal or internal use of specific clients. This consent is given on the condition, however, that the copier pay a $\$ 7.00$ per article copy fee through the Copyright Clearance Center, Inc. Operations Center, 222 Rosewood Drive, Danvers, MA 01923 for copying beyond that permitted by Sections 107 or 108 of the U.S. Copyright Law. This consent does not extend to other kinds of copying such as copying for general distribution, for advertising or promotional purposes, for creating new collective works, or for resale.

SAE routinely stocks printed papers for a period of three years following date of publication. Direct your orders to SAE Customer Sales and Satisfaction Department.

Quantity reprint rates can be obtained from the Customer Sales and Satisfaction Department.

To request permission to reprint a technical paper or permission to use copyrighted SAE publications in other works, contact the SAE Publications Group.



All SAE papers, standards, and selected books are abstracted and indexed in the Global Mobility Database

No part of this publication may be reproduced in any form, in an electronic retrieval system or otherwise, without the prior written permission of the publisher.

ISSN 0148-7191

Copyright 2001 Society of Automotive Engineers, Inc.

Positions and opinions advanced in this paper are those of the author(s) and not necessarily those of SAE. The author is solely responsible for the content of the paper. A process is available by which discussions will be printed with the paper if it is published in SAE Transactions. For permission to publish this paper in full or in part, contact the SAE Publications Group.

Persons wishing to submit papers to be considered for presentation or publication through SAE should send the manuscript or a 300 word abstract of a proposed manuscript to: Secretary, Engineering Meetings Board, SAE.

\section{Printed in USA}




\title{
A Review of Experimental and Simulation Studies on Controlled Auto-Ignition Combustion
}

\author{
Nebojsa Milovanovic and Rui Chen* \\ Department of Aeronautical and Automotive Engineering, Loughborough University
}

Copyright $@ 2001$ Society of Automotive Engineers, Inc.

\begin{abstract}
Engines with controlled auto-ignition (CAI) combustion offer a number of benefits over conventional spark ignited (SI) and compression ignited (CI) engines, such as much lower NOx emission due to its relatively low combustion temperature, negligible cycle-to-cycle variation due to its self-ignition nature, higher combustion efficiency at part load than its SI counterpart, and low soot emissions since a homogeneous lean air/fuel mixture is being employed. Unlike conventional SI and CI engines, where combustion is directly controlled by the engine management system, the combustion in CAI engines is controlled by chemical kinetics only. Over the past two decades, a number of technologies have been developed to initiate such combustion on both 2 and 4-stroke engines with various fuels, but none of them could maintain the combustion over the wide engine operation range. Remaining problems include control of ignition timing and the heat release rate over the entire engine operation range. This paper reviews some of the engine research results and available data from combustion kinetics studies. It has been observed that the quality of engine charge affects both ignition timing and the heat release rate of CAI combustion, but a certain charge temperature is essential to start the ignition of CAI combustion.
\end{abstract}

\footnotetext{
* Corresponding author. Tel. +44-1509-228176

Fax. +44-1509-223946

E-mail: R.Chen@lboro.ac.uk
}

\section{INTRODUCTION}

Controlled auto-ignition (CAI) combustion is a combustion process which utilises homogeneous air/fuel mixture, but combustion is initiated by fuel self-ignition. It therefore combines features of both SI and CI combustion. During the compression process, different parts of the charge mixture have different heat capacities due to local in-homogeneities which results in non-unified temperature distribution throughout the combustion chamber. When the hotter parts overcome their threshold energies, ignition of these zones is initiated. The energy exotherm warms and compresses the remainder of the charge, increasing the temperature, until full-scale ignition is established after a short time delay. Therefore, CAI combustion is a thermal environment related auto-ignition process, but ignition itself is controlled by the chemical kinetics of the mixture with relatively little influence of turbulence and mixing. There is no large-scale flame propagation. Potentially, CAI combustion is a third combustion principle for internal combustion engine applications.

Many other names have also been used in recognising this potential combustion strategy, such as:

- Active Thermo-Atmosphere Combustion (ATAC) [14], Activated Radicals (AR) combustion [5,6], Compressed air assisted fuel injection process (IAPAC) [7], Toyota-Soken combustion (TS) [8], etc., for two-stroke engines; 
- Homogeneous Charge Compression Ignition (HCCI) $[9,10]$, Compression Ignited Homogeneous Charge (CIHC) combustion [11], Premixed Charge Compression Ignition (PCCI), Control Auto-Ignition (CAI) combustion [12], Diesel combustion under uniform higher-dispersed mixture formation (UNIBUS) [13], etc., for four-stroke engines.

Over the past two decades, a number of technologies have been developed to initiate CAI combustion in both 2 and 4-stroke engines with various fuels, although none of them could maintain such combustion over the entire engine operation range. The problems that remain are concerned with difficult control over the entire range of engine speeds and loads, high $\mathrm{HC}$ and $\mathrm{CO}$ emissions, and high peak pressures.

The problem of controlling CAI combustion is directly linked to ignition timing management. Two requirements needing to be addressed are the start of auto-ignition should occur around top dead centre (TDC), and the rate of heat release should be controllable. Unlike SI and CI combustions where the start of ignition and the rate heat release are directly controlled by the engine management systems, in CAI combustion, these two parameters are controlled mostly by its chemical kinetics. Direct controlling methods are, therefore, not suitable for CAI engines.

There are a number of in-direct control methods, which have the potential of controlling the timing of auto-ignition and the rate of heat release of CAI combustion. These can be generally divided into two categories:

- modifying the air/fuel mixture properties by increasing intake temperature, adjusting air/fuel ratio, using EGR, using additives (promoters and inhibitors of ignition), and modifying fuels by blending or preconditioning;

- modifying engine operation and design parameters, such as the variable compression ratio, variable valve timing, supercharging, and using different concepts of fuel injection.

In this paper, a range of engine research results and available data from combustion kinetics studies were reviewed. It has been observed that although the quality of engine charge affects both ignition timing and the heat release rate of CAI combustion, a certain charge temperature is also essential to initiate the ignition of CAI combustion.

\section{FUNDAMENTALS OF CAI COMBUSTION}

Research studies on primary reference fuels (PRFs) indicated that the auto-ignition behaviour of a fuel depends largely upon its composition, molecular size and structure. $\mathrm{N}$-heptane is a reactive straight-chain paraffin and has a low octane number. Iso-octane is a less reactive branched- chain paraffin, and has a higher octane number. Within internal combustion (IC) engines, these two fuels behave differently toward auto-ignition. N-heptane is characterised by a clearly distinguished two-stage ignition: the first stage ignition, which is also regarded as "cool flame", with negative temperature coefficient (NTC) behaviour, followed by the main ignition stage. Iso-octane undergoes a single-stage ignition only. The difference between the two ignition mechanisms has important consequences on the control of the CAI combustion [14$25]$.

At low temperature, the rate of chain branching for a straight-chain paraffin (n-heptane) is much more intense than that of branched-chain paraffin (iso-octane). This is due to the structure of $\mathrm{C}_{7} \mathrm{H}_{15}$ radicals which leads to higher rates of $\mathrm{RO}_{2}$ isomerization which causes chain branching from ketohydroperoxide decomposition [17, 23]. Lower reactivity of the branched-chain paraffin (iso-octane) is due not only to the large number of less reactive methyl groups but also to the presence of tertiary and quaternary $\mathrm{C}$ atoms in its structure. The homolysis reactions of tertiary and quaternary structures compete with ketohydroperoxide formation, contributing to the lower reactivity of branched-chain paraffin's [18]. All of these indicate that a fuel which has a long-chain and many weakly bounded $\mathrm{H}$ atoms has high isomerization rates, which leads to rapid ignition. For compact and highly branched fuels with a large fraction of strongly bounded $\mathrm{H}$ atoms, ignition is inhibited [16].

Chain branching processes play a major role in controlling the ignition of hydrocarbons. For hydrocarbons with twostage ignition behaviour, the first stage of ignition is the result of "cool flame" combustion and NTC behaviour, which were explained in detail by low temperature $(\mathrm{T}<1000 \mathrm{~K})$ chemical kinetics analysis [14,17,18, 24-25]. At lower temperatures (up to $900 \mathrm{~K}$ ), ignition is controlled by degenerative chain branching processes. These chain branching processes are characterised by producing chain branching precursors, $\mathrm{RO}_{2}$ radicals, which start to decompose above $800 \mathrm{~K}$. The decomposition of $\mathrm{RO}_{2}$ radicals leads to an inverse temperature dependence of the overall reaction rate-NTC [26]. At an intermediate temperature (900 to $1100 \mathrm{~K})$, chain branching is introduced by the following sequences [26]:

$\mathrm{RH}+\mathrm{HO}_{2} \rightarrow \mathrm{H}_{2} \mathrm{O}_{2}+\mathrm{R}$

$\mathrm{H}_{2} \mathrm{O}_{2}+\mathrm{M} \rightarrow \mathrm{OH}+\mathrm{OH}+\mathrm{M}$

where $\mathrm{M}$ is any non-reactive third-body.

This sequence is important since it precedes the second stage of ignition, i.e. the main ignition. During the preceding time, (also known as induction time), and temperatures up to $1000 \mathrm{~K}, \mathrm{H}_{2} \mathrm{O}_{2}$ concentration increases steadily since the decomposition reaction rate is much slower than the production reaction rate. When a temperature of about $1000-1050 \mathrm{~K}$ is reached, the reaction $\mathrm{H}_{2} \mathrm{O}_{2}+\mathrm{M} \rightarrow \mathrm{OH}+\mathrm{OH}+\mathrm{M}$ accelerates, which results in producing large amount of $\mathrm{OH}$ radicals. Most of these $\mathrm{OH}$ 
radicals then react with fuel molecules, produce water, heat and subsequently further increase the temperature of the reacting mixture $[27,28]$.

When the temperature is sufficiently high (over $1100 \mathrm{~K}$ ), the high temperature chain branching sequence $\left(\mathrm{H}+\mathrm{O}_{2} \rightarrow \mathrm{O}+\mathrm{OH}\right)$ takes place and quickly dominates the overall reaction. The main ignition starts. This main ignition temperature is identical for almost all fuels [16]. This unity shows a distinctive feature that the high temperature chain branching reaction is fuel type independent. Results from simulations of n-heptane and iso-octane with CAI combustion [29], cited in Figures 1 and 2, confirmed that both fuels ignited (main ignition) when air and fuel mixture reached a temperature of 1100K. Results from experimental studies on CAI combustion [1-13, 30-43] proved the consistency of this temperature and its independence from fuel type.

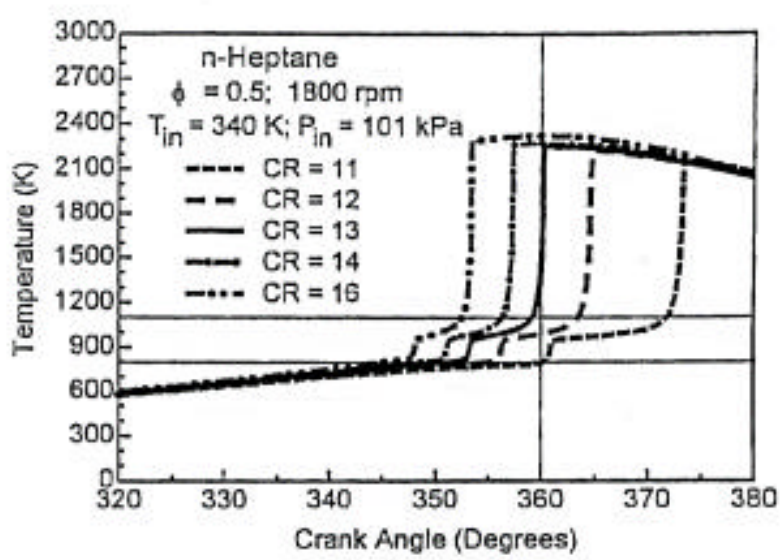

Figure 1. Gas temperature as a function of crank angle for n-heptane during various CR [29]

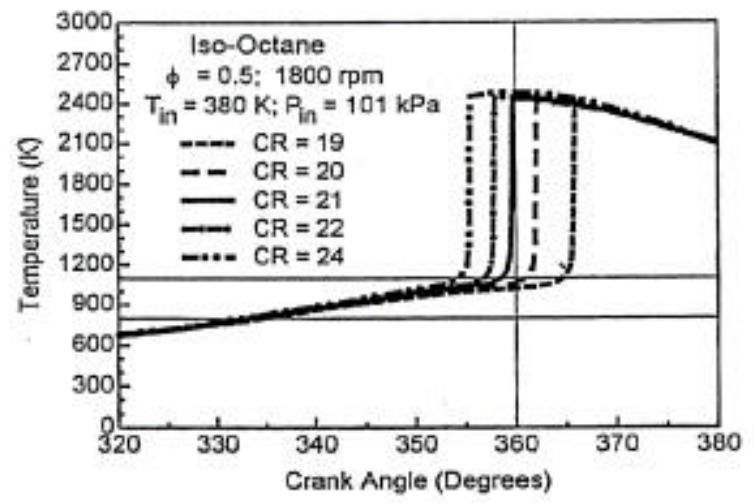

Figure 2. Gas temperature as a function of crank angle for iso-octane during various CR [29]

The effect of fuel molecular structure on the first and main stage of ignition is shown in Figure 3 [28]. Three isomers of pentane were compared at the same experiment temperature. It was found that n-pentane ignited firstly, followed by neo-pentane and finally iso-pentane. The main ignitions occurred at the same temperature, but the time required to reach such a temperature, which was the ignition delay, was different. N-pentane displayed the highest rate of ignition since its first-stage of ignition provided the highest temperature increase of the three fuels. In other words, the time required for main ignition depends on the heat released from the first stage of ignition, which determines the rate of temperature increase, although the total heat release during the first stage of ignition (low temperature regime) is considerably lower than that in the main ignition stage. This phenomenon was cited in Figure 4, obtained from the CAI combustion with n-butane and air mixture [43] at different compression ratios. Two peaks of heat release rates were observed, where the first peaks indicated the heat released during the first stage of ignition.

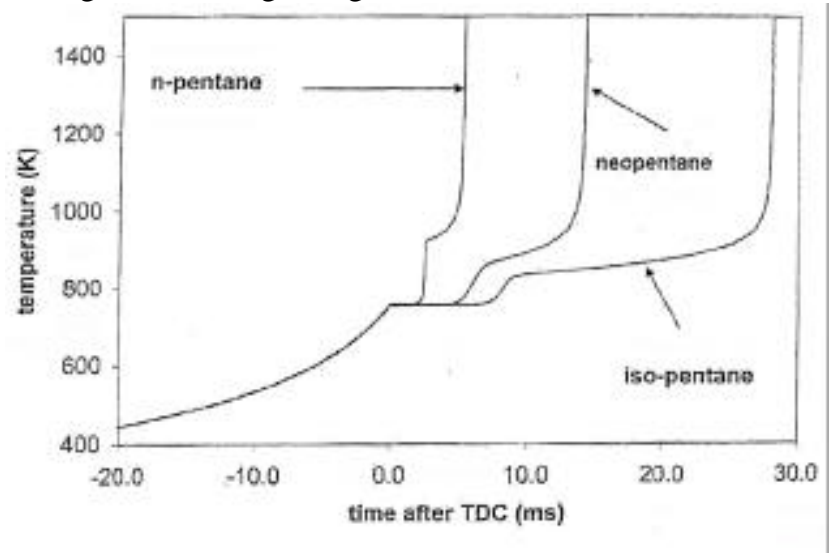

Figure 3. Temperatures of ignition as a function of time for three pentanes' isomers [28]



Figure 4. Temperature and heat release rate as a function of crank angle for n-butane/air CAI combustion with two different CR (15.7:1 and 16.1:1) [43]

ADVANTAGES OF CAI COMBUSTION - Unlike conventional SI and CI combustions, CAI combustion uses a homogenous air and fuel mixture, no centralised combustion initiation is required, and the entire charge gives a parallel energy release throughout the entire charge. The advantage of such auto-ignition and simultaneous combustion nature is that the combustion limit towards leaner fuel-air mixtures can be significantly 
extended. The low heating value of lean mixtures lowers the peak temperature of combustion. Combustion temperature below the temperature of NOx formation $(<1800 \mathrm{~K})$ [44] had been seen as a major advantage of the CAI combustion. Results cited in Figures 5, [33] indicated that NOx emission had been significantly reduced by CAI combustion compared with conventional CI and SI combustion. These results were obtained during part load operation with natural gas.

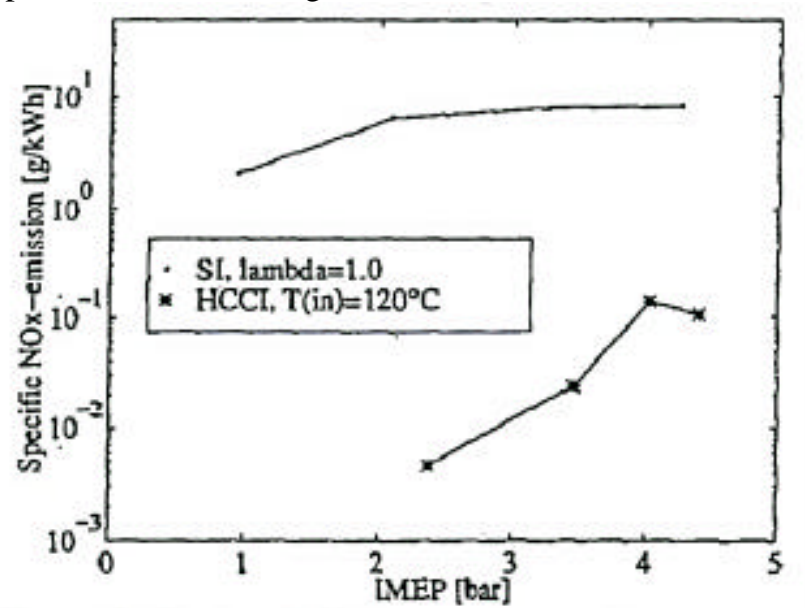

Figure 5. Specific NOx emission as a function of IMEP during CAI (HCCI) and spark ignition (SI) combustions of natural gas [33]

Compared to SI combustion, CAI combustion has negligible cycle-to-cycle variations. Experimental results on gasoline [45] are shown in Figure 6. It can be seen that large cycle-to-cycle variations occur with SI combustion since the early flame development varies significantly with the variation of air/fuel mixture strength in the vicinity of a spark plug. However, the combustion initiation of CAI takes place at many points simultaneously, and the unstable flame propagation is avoided.

At part load conditions, un-throttled engine control strategy could be employed with CAI combustion in order to reduce pumping losses [1, 33], since CAI combustion can be achieved at a relatively high air/fuel ratio. The high endurance to exhaust gas recirculation (EGR) of CAI combustion can be another potential solution to the technology.

Compared to SI, high compression ratios are preferred by CAI combustion due to its self-ignition nature. Therefore, a higher thermal efficiency can be obtained. Results obtained from an experimental study [33] are shown in Figure 7, where CR was 21:1 for CAI combustion, and 12:1 for SI.

Fuel rich zones are the main source of particulate emissions in conventional CI engines. However, with CAI strategy, air and fuel mixture are pre-mixed before combustion starts, and thus very low soot emissions can be achieved [40].
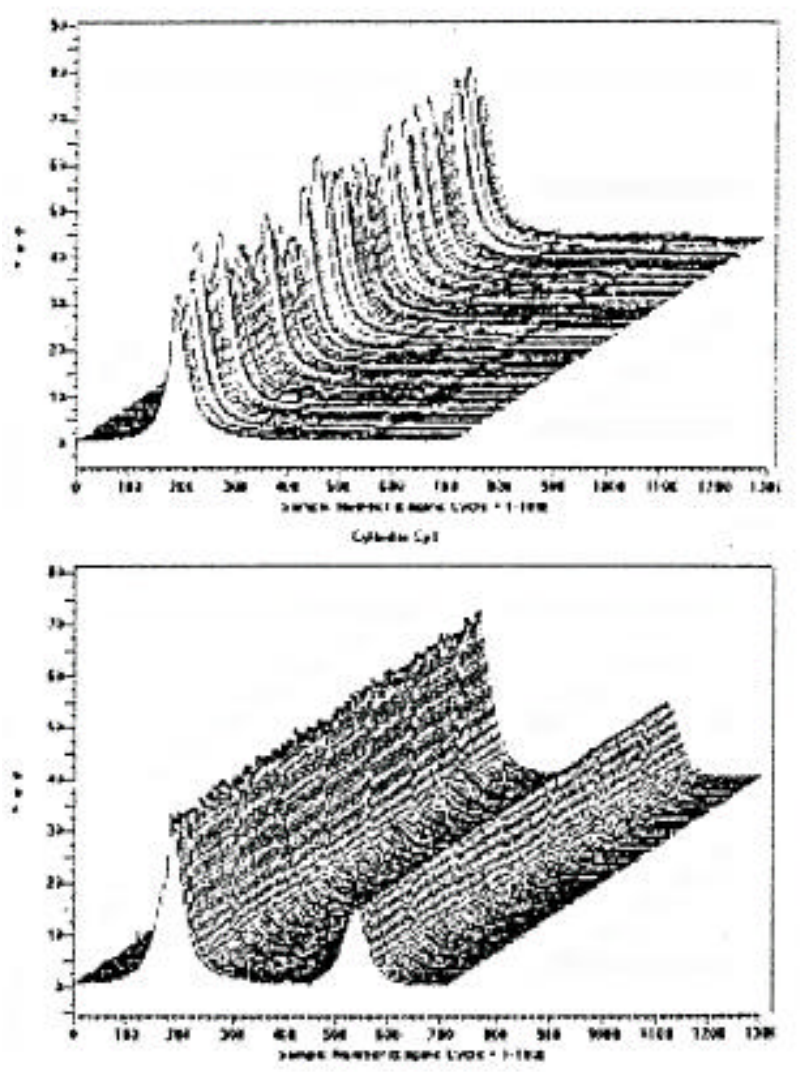

Figure 6. Cycle-to-cycle variations as a function of crank angle for SI (upper frame) and CAI combustion of gasoline [45]

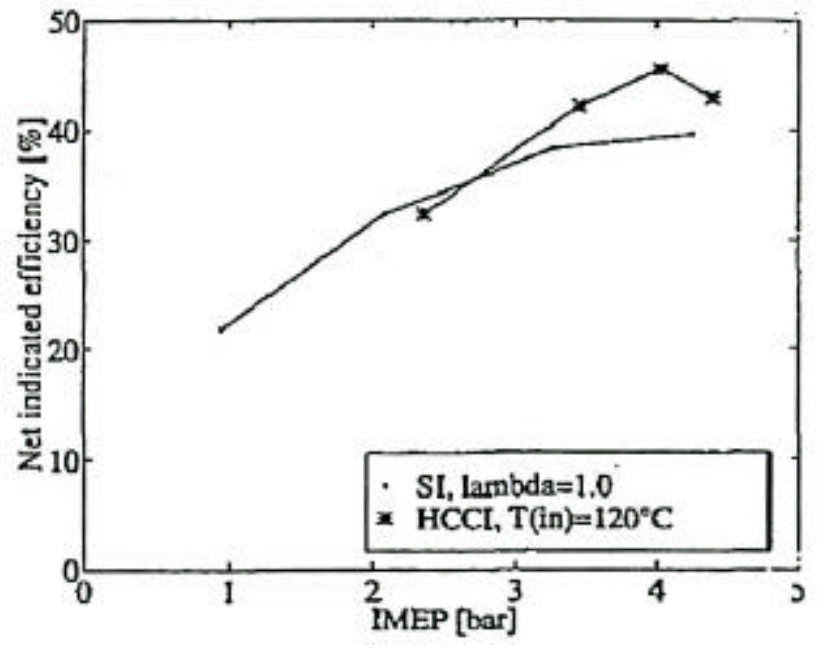

Figure 7. Net indicated efficiency as a function of IMEP for CAI (HCCI) and spark ignition (SI) combustion of natural gas [33]

DISADVANTAGES OF CAI COMBUSTION - One of major drawbacks, which limits the commercial application of CAI combustion in road vehicle engines, is the difficulty in maintaining CAI combustion over the entire load range. This difficulty is reflected by the controls over ignition timing and rate of heat release. Primarily, the CAI 
combustion process is controlled by chemical ignition kinetics. Direct control methods such as those applied on SI and CI engines cannot be used. As a result, high peak pressure accompanied with a high rate of heat release and knock related problems could occur if rich mixtures were used [33-35, 40-42]. $\mathrm{CO}$ and $\mathrm{HC}$ emissions from CAI combustion could be higher than conventional CI [41] and SI [33] engines, too. In the engine combustion chamber with the CAI strategy, the combustion temperature is generally lower than conventional CI and SI, and it decreases faster in the expansion stroke. Thus, fuels in boundary layers and crevices have less chance of joining the late stage of combustion [28]. This may be the reason of $\mathrm{HC}$ emissions. Partial burning of those fuels at a later stage of expansion, due to temperature decreases, may contribute to a higher emission of $\mathrm{CO}$.

\section{CAI COMBUSTION IN 2-STROKE ENGINES}

CAI combustion was recognised initially in two-stroke engines in the late 70s by Onishi et al [1]. It was observed that premixed air/fuel mixture could self-ignite at many points simultaneously, without obvious flame propagation. Later, Noguchi et al [8], also obtained such combustion in an opposed piston two-stroke engine. Since then, researches into CAI combustion in two-stroke engines have made tremendous progress. In 1996, Honda built a two-stroke engine with CAI combustion concept and proved its performance and reliability by winning the fifth place in Granada-Dakar rally competition.

Different from four-stroke engines, two-stroke engines have relatively shorter intermittent breaks between combustion events and produce a larger amount of residual gases at high temperature inside combustion chambers particularly in part load conditions. These conditions make two-stroke engines more favourable for CAI combustion than their four-stroke counterparts. Results from Ishibashi et al $[5,6,31,32]$ confirmed the dependency of CAI combustion on in-cylinder gas temperature from various engine operational conditions. Recently they performed a further experimental study [33] on the impacts of various engine parameters on CAI combustion stability. Results indicated that CAI could only be controlled in a certain part of entire load range. At high loads, combustion cannot be maintained without the assistance of a spark ignition, both CAI and SI, therefore, have to be employed.

\section{CAI COMBUSTION IN 4-STROKE ENGINES}

A number of worldwide experimental studies using the CAI combustion concept in 4-stroke engines have been carried out in recent years. The major target among these studies was to achieve a stable CAI combustion over a wide range of engine operating conditions. In general, two possible directions have been investigated: modifying air/fuel mixture properties, and modifying engine operation and design parameters.
MODIFICATIONS IN AIR/FUEL MIXTURE PROPERTIES - The purpose of these modifications is to alter the reactivity of intake charge by changing its thermo-chemical properties, thus influencing CAI combustion.

Intake temperature - A higher intake temperature gives a higher heat release rate. It improves the start of first stage ignition (cool flame) and thus reduces main ignition delay. One popular method of generating CAI combustion and controlling the ignition timing is to adjust the intake air temperature [17-28]. A higher intake temperature advances CAI combustion but the controllable range is limited. Outside this range, the engine volumetric and thermal efficiency can be largely reduced, due to the fact that if ignition is advanced into the compression stroke, it will cause significant negative work on the piston.

Air/fuel ratio - The strength of the air/fuel mixture has a direct effect upon CAI timing and its combustion heat release rate [31-44, 46]. Enriching the mixture decreases the ratio of the specific heats $(\gamma)$ and thus reduces the amount of disposable compression heating in the charge. Consequently, the mixture has to be compressed further to reach ignition temperature. The ignition timing is therefore delayed.

Exhaust Gas Recirculation (EGR) - Two CAI combustion control strategies with EGR have been identified and investigated: trapping hot internal EGR, and adding cool external EGR into engine fresh charge.

Trapping hot residual EGR will increase the engine charge temperature when air/fuel mixture blends with it inside the combustion chamber. By tuning the quantity of residual EGR, ignition delay and heat release rate of CAI combustion can be adjusted [45].

External EGR has a much lower temperature than internal EGR, and it will reduce the chemical reaction rate, thus delaying the ignition time, reducing the heat release rate, and lowering peak cylinder pressure. Christensen et al [36] performed a series of experimental studies by introducing EGR into engine inlet manifold. Reported results revealed that stable CAI combustion could be achieved when using up to $57 \%$ of EGR with isooctane, $62 \%$ with ethanol and $48 \%$ with natural gas. The compression ratio was 18:1, IMEP around 5 bar and the inlet temperatures of air/fuel mixture were about 120,110 and $150^{\circ} \mathrm{C}$, respectively. Stable CAI combustion with diesel fuel at conditions of higher air/fuel mixture intake temperature $\left(175-240^{\circ} \mathrm{C}\right)$, lower compression (8:1) ratio, with up to $50 \%$ of EGR was also achieved in a certain load range [24].

Additives - Some chemical components have the ability to inhibit or promote heat release at the first stage of ignition. If it is mixed with engine charge as an additive, it will 
affect the heat release of the first stage ignition of CAI combustion, then further influence the main ignition.

Dimethyl-ether (DME) has a low Octane number. When it is mixed with conventional fuels, it will promote the rate of heat release at the first stage of ignition, and thus stabilise CAI combustion. The rate of heat release from the first stage of ignition with methane is very modest. This makes the main ignition of methane very difficult to achieve in an engine cycle compared with other fuels. Experimental results obtained on a Co-operate Fuels Research (CFR) engine [46] showed that improved CAI combustion could be obtained by adding DME into methane ( $15 \%$ by volume).

Water is an inertial chemical component. As a potential additive to fuels, it affects the ignition timing and heat release rate of CAI. Experimental results [38] showed that the start of ignition was delayed and the rate of CAI combustion was slowed down with water injection, but only within a narrow range of load. On the other hand, unburned $\mathrm{HC}$ and $\mathrm{CO}$ emissions increased, which indicated that the combustion quality was reduced.

Fuel modifications - Fuel reactivity towards self-ignition is influenced by its composition, molecule size and structure. Fuel pre-conditioning or different fuels blending can make some fuels more favourable for CAI combustion, and make the combustion controlling process more achievable.

By separating a premium liquid fuel with standard 95 Octane number into vapour and liquid fractions, different octane numbers were found. The Octane number of vapour phase became 90, while the liquid phase remained unchanged [47]. The fraction with lower octane number is more suitable for CAI combustion due to its superior autoignition characteristic.

Blending fuels with different auto-ignition abilities can significantly change the CAI combustion performance. Blending DME into methane can improve the CAI combustion of methane by expanding the controllable range and reducing emissions, especially at light load [44]. On the other hand, different fuel blending formats can also be used to limit the operational range of the CAI combustion. Experiment study results from a blended fuel ( $19 \%$ of hexadecane and $81 \%$ of heptane) showed that the suitable air/fuel ratio range for CAI combustion narrowed much more significantly with an increased compression ratio [42] than neat diesel fuel [41].

MODIFICATIONS OF ENGINE OPERATION AND CONTROL PARAMETERS - The purpose of modifying the engine operation and control parameters is basically to achieve and to stabilise CAI combustion by altering the time-temperature history of engine charge, for various engine operating conditions.
Compression Ratio - A higher compression ratio increases the charge temperature and therefore advances the start of ignition of the CAI combustion [34-41]. In addition, higher compression and thus expansion ratios contribute to higher thermal efficiency. However, knock can be a problem when a high compression ratio is used, particularly with lower octane number fuels.

Engine speed - The ignition delay of CAI combustion depends largely on air/fuel mixture performance and is relatively free from engine speed influences. However, it should be noted that the ignition time of CAI combustion relative to the engine crank angle should be retarded when the engine speed increases [34-40]. In the case that ignition occurs before TDC, the temperature rise from compression will compensate the relative ignition retardation at high engine speed. If ignition appears after TDC, the relative ignition delay caused by high engine speed will be further retarded by expansion, which slows down the temperature rise.

Variable valve timing (VVT) - Flexible active valve train (AVT) has been used in controlling the CAI combustion process by Lotus [45]. By tuning the engine valve timing, a manageable quantity of internal EGR can be trapped and used to heat fresh charge by directly mixing up to the required ignition temperature, just like CAI combustion in 2-stroke engines. AVT has been adjusted to work in two modes: sequential and simultaneous trapping of EGR and fresh charge. Promising results in reducing pollutant emissions, fuel consumption as well as in controlling CAI combustion at lean conditions have been obtained.

Supercharge - Supercharging can be used to increase the engine's IMEP, and extend the operational range of air/fuel ratio of the CAI combustion. Different fuels have been tested with various compression ratios and boost pressures. Results have shown that supercharging (up to 2bar boost pressure) increases attainable IMEP, and broadens the operational air/fuel ratio range, although the inlet temperature needs additional adjustment [35]. However, supercharging is accompanied by a high cylinder pressure (around 250bar for 2bar boost pressure), this may limit its potential application.

Heavy fuel injection - Port fuel injection or fumigation of heavy fuels, such as diesel, with CAI combustion often results in high $\mathrm{HC}$ and $\mathrm{CO}$ emissions and high fuel consumption due to a poor vaporisation process and wall interaction within the combustion chamber [12, 48-53]. Direct injection has been under investigation, too. Two direct injection concepts can be used: early fuel injection, and late fuel injection.

Using the early in-cylinder fuel direct injection strategy, fuel is injected during early part of compression stroke. Fuel vaporisation draws heat from surrounding gases, and significantly affects the time-temperature history of the 
entire mixture. Experimental results obtained with early injection of diesel fuel show good results regarding emission reduction [54].

The late in-cylinder fuel direct injection strategy is a relatively new approach to obtain "homogenous" diesel CAI combustion, as reported by Nissan [55]. During low load, fuel was injected around TDC. The ignition timing was managed by EGR, reduction in CR and strong swirl. As a result, combustion appeared well after the end of fuel injection and the combustion jet that is usually associated with conventional CI engines was eliminated. However, this method suffers from short ignition delay if EGR, reduction in CR and swirl are not employed.

\section{SIMULATION STUDIES ON CAI COMBUSTION}

There are significantly less CAI combustion simulation analyses reported in the literature than experimental ones. Fluid mechanic codes, like KIVA, with relatively simplified chemical kinetic models have been used [5658]. These models are generally limited in accuracy due to simplified chemical kinetics which do not give satisfactory results under all possible operating conditions. Detailed kinetic codes have also been used to analyse CAI combustion [59, 60]. Most of these simulations use zerodimensional single-zone models, and assume a cylinder to be a "lumped" volume with unified composition and thermodynamic properties. These assumptions are acceptable to CAI combustion, where mixing is not a controlling factor.

Impacts of compression ratio, engine speed, air/fuel ratio and EGR on the ignition timing of CAI combustion with primary reference fuels: n-heptane and iso-octane, have been analysed using a single-zone model with adiabatic compression and expansion assumptions in [29]. Results suggested that iso-octane allows a higher compression ratio than n-heptane, thus has the potential for better efficiency. Engine operating conditions have a reduced effect upon ignition timing for iso-octane than n-heptane.

Single-zone with heat transfer correlation [61] has been used to simulate and analyse the impacts of $\mathrm{CR}$ and residual gas trapping (RGT) on ignition timing, burn duration and $\mathrm{HC}$ and $\mathrm{CO}$ emissions of CAI combustion with methane $[62,63]$. The heat transfer correlation employed in the model ignored spatial variations in the cylinder, and assumed heat loss as a distributed function which was proportional to the temperature difference between the average gas temperature and the time averaged wall temperature. The simulated results indicated that an acceptable region of controlled CAI combustion (efficiency above 50\% and NOx emission bellow 100ppm) could be achievable at high air/fuel ratios $(\lambda>2)$ and high CR (up to 18:1) with supercharging (boost pressure 3 atmosphere).
The model used in [62,63] introduced heat transfer correlation, therefore reduced over-predictions in peak cylinder pressure and NOx emission predicted by the model used in [29] where adiabatic compression and expansion had been assumed. However, both models suffer from oversimplification of real conditions within the combustion chamber. In practice, the boundary layer, which contains significant mass, has a lower temperature than the bulk gas inside the combustion chamber. The fuels inside the boundary layer and crevices can only be burnt during the very late stage of combustion when their temperature rises to the required levels, and their combustion extends over the entire heat release process. By assuming unified temperature throughout the entire combustion chamber, the estimated combustion duration and heat release process is reduced, therefore, peak cylinder pressure, and pressure rise rate are overestimated. Additionally, $\mathrm{CO}$ and $\mathrm{HC}$ emissions cannot be predicted accurately. However, the ignition timing of CAI combustion and NO emission are dependent on the temperature history of the bulk gas inside, the predicted results agree well with experimental data [18].

By coupling the fluid mechanic code with the detailed chemical kinetic code, a multi-zone model has been developed by Aceves et al [27]. In this study, the KIVA code was used to calculate the temperature distribution within the cylinder under motored conditions. The cylinder was divided into 10 zones, in order to locate enough zones within major crevices and the boundary layer. Results from the KIVA code were then utilised in the chemical kinetic code, as inputs to calculate the CAI combustion heat release rate as a function of pressure, temperature and gas composition [59]. Good agreement in maximum cylinder pressure, combustion duration and combustion efficiency with results from the experimental study in [18] was obtained. The estimation of $\mathrm{HC}$ and $\mathrm{CO}$ emissions showed lower accuracy, probably due to insufficient crevices being included [27]. Despite largely improved accuracy in comparison with single-zone models, the model used in [27] still requires a significant amount of computational time, about 30 hours for the KIVA code followed by 12 hours for the detailed chemical kinetics code. (The time required for models in [29 and 62,63] is several orders of magnitude less.)

A model with a stochastic approach, which includes effects of turbulent mixing and diffusion together with detailed chemical kinetics, has been used for analysing CAI combustion with natural gas [64]. The fact that the boundary layer and the air/fuel mixture in the crevices are significantly cooler than bulk gas was included into the model. The partially stirred plug flow reactor model, a stochastic reactor model, was employed for modelling the turbulent mixing between boundary layer, crevices and the turbulent core together with chemical reactions within the cylinder. The detailed chemical kinetic mechanism for natural gas combustion was incorporated in the stochastic reactor model. Predicted results showed good agreement in 
ignition timing, combustion duration, cylinder peak pressure, and $\mathrm{HC}$ and $\mathrm{CO}$ emissions with experimental results obtained in [18]. The improved prediction in $\mathrm{CO}$ and $\mathrm{HC}$ emissions, compared with results from the model used in [27], may be due to the consideration of turbulent mixing between boundary layer, crevices and the turbulent core gas.

\section{CONCLUSIONS}

The CAI combustion strategy has the potential to reduce NOx and soot emissions and improve part load engine efficiency. It is suitable for a variety of fuel types. However, to achieve a successful commercial application, problems such as control of ignition timing and heat release rate over the entire engine operation range, have to be solved.

CAI combustion needs an essential ignition temperature. The methods used to achieve such a temperature have to be able to manage the rate of heat release followed by ignition and avoid extreme sharp pressure increases.

The results obtained from experimental investigations and theoretical simulation studies have indicated that the control over CAI combustion can be achieved with lean mixtures in a limited range $(\lambda>2)$ by using various engine control strategies and air/fuel mixture modifications.

Variable CR and valve timing technologies are potential control technologies for CAI combustion. Late fuel incylinder direct injection can be an ideal strategy for CAI combustion with heavy fuels, such as diesel at low loads.

Since the main ignition of CAI combustion occurs at a certain temperature, which is independent of fuel types, modification of the air/fuel mixture by fuel blending or using various additives can only control CAI combustion via their effects on the heat release rate during first stage ignition. The selection of additives should be in agreement with the fuel type and its octane number.

Future experimental investigations should focus on variable valve timing, late in-cylinder injection for heavy fuel in particular, and supercharging. These potential technologies can be applied individually or combined in various forms.

Most calculations have so far been done using closed cycles. In future, further theoretical simulation studies should include the impacts between intake and exhaust flows over the entire engine cycle. The impact between intake and exhaust flows has serious effects upon the temperature time history of the charge inside the combustion chamber. Therefore, it is anticipated that such an impact may have a serious effect on CAI combustion as well, since CAI combustion is very sensitive to charge temperature time history.
Using a lean air/fuel mixture or diluting a richer mixture largely with EGR can control the heat release rate of CAI combustion, but it will result in poor power output. SI offers a high power output density. A hybrid CAI-SI strategy can therefore operate the engine with CAI at low loads to improve emission and efficiency, without sacrificing the high load performance where SI strategy can be used.

For engines utilising heavy fuels, CAI has the potential to significantly reduce soot and NOx emissions without sacrificing fuel efficiency. However, this benefit can only be considered when the engine load is low. At high load, fuel enrichment would largely increase the heat release rate of CAI combustion and result in an extremely high cylinder pressure increase, due to the nature of simultaneous combustion throughout the entire combustion chamber. At high load, conventional CI may still have to be employed.

\section{REFERENCES}

1. Onishi, S., Jo, S.H., Shoda, K., Jo, P.D., and Kato S., "Active Thermo -Atmosphere Combustion (ATAC) A new Combustion process for Internal Combustion Engines", SAE Paper 790501, 1979.

2. Ogume, H., Ichikura, T., Iida, N., "A Study on Adaptability of Alternative Fuels for Lean Burn TwoStroke ATAC Engine”, SAE Paper 972097, 1997.

3. Iida, N., "Alternative Fuels and Homogenious Charge Compression Ignition Combustion Technology", SAE Paper 972071, 1997.

4. Esterlingot, E., Guilbert, P., Lavy, J., Raux, S., "Thermodynamical and Optical Analyses of Controlled Auto-ignition Combustion in Two Stroke Engines", SAE Paper 972098, 1997.

5. Ishibashi, Y., Isomura, S., Kudo, O., Tsushima, Y., "Improving the Exhaust Emissions of Two-Stroke Engines by Applying the Activated Radical Combustion”, SAE Paper 960742, 1996.

6. Ishibashi, Y., Asai, Y., Nishida, K., “An Experimental Study of Stratified Scavenging Activated Radical Combustion Engine”, SAE Paper 972077, 1997.

7. Duret, P., Venturi, S., "Automotive Calibration of the IAPAC Fluid Dynamically Controlled Two Stroke Combustion Process" SAE Paper 960363, 1996.

8. Noguchi, M., Tanaka, Y., Tanaka, T., Takeuchi, Y., "A study on Gasoline Engine Combustion by Observation of Intermediate Reactive Products During Combustion”, SAE Paper 790840, 1979.

9. Thring, R.H., "Homogenous Charge Compression Ignition (HCCI) Ehgines” SAE Paper 892068, 1989. 
10. Ryan, T.W., Erwin, J., "Effects of Fuel Properties and Composition on the Temperature Dependent Autoignition of Diesel Fuel Fractions", SAE Paper 922229, 1992.

11. Najt, P.M. and Foster, D.E., " Compression-Ignited Homogenous Charge Combustion", SAE Paper 830264, 1983.

12. Aoyama, T., Hattori, Y., Mizuta, J., Sato, Y., "An Experimental Study on Premixed-Charge Compression Ignition Gasoline Engines", SAE Paper 960081, 1996.

13. Yanagihara, H., Sato, Y., Junichi, M., "A Study of Diesel Combustion under Uniform Higher-Dispersed Mixture Formation", JSAE 9733675, 1997.

14. Westbrook, K.C., et al, "A Detailed Chemical Kinetic Reaction Mechanism for the Oxidation of Iso-Octane and n-heptene Over an Extended Temperature Range and its Application to Analysis Of Engine Knock", $22^{\text {nd }}$ International Combustion Symposium, 1988, pp. 893-901.

15. Westbrook, K.C., et al, "The Autoignition Chemistry of Paraffinic Fuels and Pro-Knock and Anti-Knock Additivies: A Detailed Chemical Kinetic Study", SAE Paper 912314, 1991.

16. Chevalier, C., et al "Hydrocarbon Ignition: Automatic Generation of Reaction Mechanisms and Applications to Modelling of Engine Knock", 24 ${ }^{\text {th }}$ International Combustion Symposium, 1992, pp. 93-101.

17. Griffiths, J., et al "Extents of Alkane Combustion During Rapid Compression Leading to a Single and Two-Stage Ignition", $26^{\text {th }}$ International Combustion Symposium, 1996, pp. 2685-2692.

18. Callahan, C.V., et al "Experimental Data and Kinetic Modelling of Primary Reference Fuel Mixtures", $26^{\text {th }}$ International Combustion Symposium, 1996, pp. 739746.

19. Warnatz, J., et al "Kinetic Modelling of the Oxidation of Large Aliphatic Hydrocarbons", $26^{\text {th }}$ International Combustion Symposium, 1996, pp. 773-780.

20. Curran, H.J., et al "An Intermediate Temperature Modelling Study of the Combustion of Neopentane", $26^{\text {th }}$ International Combustion Symposium, 1996, pp. 641-649.

21. Come, G.M., et al "Computer-Aided Design of GasPhase Oxidation Mechanisms-Application to the Modelling of n-Heptahe and Iso-Octane Oxidation", $26^{\text {th }}$ International Combustion Symposium, 1996, pp. $775-762$

22. Griffiths, J., et al "Spontaneous Ignition Delays as a Diagnostic of the Propensity of Alkanes to Cause Engine Knock", Combustion and Flame, Vol. 111, pp. 327-337, 1997.
23. Curran, H.J., et al "Oxidation of Automotive Primary Reference Fuels at Elevated Pressures", 27 International Combustion Symposium, 1998, pp. 379387.

24. Curran, H.J., et al. "A Comprehensive Modelling Study of n-Heptane Oxidation", Combustion and Flame, Vol. 114, pp. 149-177, 1998.

25. Griffiths, J. and Barnard, J., "Combustion and Flame", $3^{\text {rd }}$ edition, Blackie Academic \& Professional, ISBN 0751401994, 1995.

26. Warnatz, J, et al "Modelling of Chemical Reaction Systems”, Springler Verlagh, Heilderberg, 1981.

27. Aceves, S.M., et al "A Multi-Zone Model for Prediction of HCCI Combustion and Emission", SAE Paper 2000-01-0327.

28. Westbrook, C.K. "Chemical Kinetics of Hydrocarbon Ignition in Practical Combustion Systems", $28^{\text {th }}$ International Combustion Symposium, Edinburgh, 2000 .

29. Kelly-Zion, P. and Dec, E.J., "A Computational Study of the Effect of Fuel-Type on Ignition Time in HCCI Engines", 28 ${ }^{\text {th }}$ International Combustion Symposium, Edinburgh, 2000.

30. Ishibashi Y., et. all, "A Trial for Stabilizing Combustion in Two-Stroke Engines at Part Throttle Operation", in "A New Generation of Two-Stroke for the Future”, edited by Pierre Duret, France, 1993

31. Ishibashi Y. and Asai M., "A Low Pressure Pneumatic Direct Injection Two-Stroke Engine by Activated Radical Combustion Concept “, SAE Paper 980757, 1998.

32. Ishibashi Y., "Basic Understanding of Activated Radical Combustion and Its Two-Stroke Engine Application and Benefits", SAE Paper 2000-01-1836, 2000.

33. Christensen, et. all, "Homogenous Charge Compression Ignition (HCCI) Using Isooctane, Ethanol and Natural Gas-A Comparison with Spark Ignition Operation”, SAE Paper 972874, 1997.

34. Christensen, et. all, "Supercharged Homogenous Charge Compression Ignition", SAE Paper 980787, 1998.

35. Christensen, et. all, "Influence of Mixture Quality on Homogenous Charge Compression Ignition", SAE Paper 982454, 1998.

36. Christensen, et. all, "Homogenous Charge Compression Ignition Engine: Experiments and Detailed Kinetic Calculations", COMODIA '98, Japan, 1998. 
37. Christensen, et. all, "Homogenous Charge Compression Ignition with Water Injection", SAE Paper 1999-01-0182, 1999.

38. Christensen, et. all, "A Study of the Homogenous Charge Compression Ignition Combustion Process by Chemiluminescence Imaging", SAE Paper 1999-013680, 1999.

39. Christensen, et. all, "Demonstrating the multi-fuel capability of a homogenous charge compression ignition engine with variable compression ratio", SAE Paper 1999-01-3679, 1999.

40. Ryan III, T.W. et. all," Homogenous Charge Compression Ignition of Diesel Fuel", SAE Paper 961160, 1996.

41. Ryan III, T.W. et. all," Homogenous Charge Compression Ignition (HCII) of Diesel Fuel", SAE Paper, 971676, 1997.

42. Iida N., Y., "Auto-Ignition and Combustion of nButane and DME/Air Mixtures in a Homogenous Charge Compression Engine", SAE Paper 2000-011832,2000

43. Kamai, T., et. all, "Effects of a Hybrid Fuel System With Diesel and Premixed DME/methane Charge on Exaust Emissions in a Small DI Diesel Engine", SAE Paper 1999-01-1509, 1999.

44. Jurgen Willand, et all, "The Knocking Syndrome-Its Cure and Its Potential”, SAE Paper 982483, 1998.

45. Low, D., et all., "4-Stroke Active Combustion (Controlled Auto-Ignition) Investigations Using a Single Cylinder Engine with Lotus Active Valve Train (AVT)", Internal report, 2000.

46. Flowers, et. all, "HCCI in a CFR Engine: Experiments and Detailed Kinetic Modelling", SAE Paper 2000-010328, 2000.

47. Lavy, J., et al., "Innovative Ultra-low NOx Controlled Auto-Ignition Combustion Processfor Gasoline Engines: the 4-Space Project", SAE Paper 2000-011837,2000

48. Stokinger, M., H., et. all, "Versuche and einem Gemischansugenden Verbrebbugdmotor mit Selbszundung", MTZ, vol 53, 1992.

49. Osses, M., et. all, "Diesel Fumigation Partial Premixing for Reduced Particulate Soot Fraction Emissions", SAE Paper 980532, 1998.

50. Ogawa, H., et all, "Combustion Mechanism Analysis with In-Chamber Gas Composition Measurement in a Premixed Lean Compression ignition Engine" COMODIA '98, Japan, 1998.

51. Furutani, et all, “An Ultra-Lean Premixed Compression Ignition Concept and its Characteristics”, COMODIA '98, 1998.
52. Iwabuchi, Y., et all. "Trial of New Concept Diesel Combustion System - Premixed Compression Ignited Combustion”, SAE Paper 1999-01-0185, 1999.

53. Nagakome, K., N., et. all, "Combustion and Emissions Characteristic of Premixed Lean Diesel Combustion Engine”, SAE Paper 970898, 1997.

54. Takeda, Y.,N., et. all, "Emissions Characteristic of Premixed Lean Diesel Combustion with Extremely Early Staged Fuel Injection", SAE Paper 961163, 1996.

55. Mase, Y., et all., "Nissan's New Multi-valve DI Diesel Engine Series”, SAE Paper 981039, 1998.

56. Amsden, A.A., "KIVA-3: A Kiva Program with Block-Structured Mesh for Complex Geometries", Los Alamos National Laboratory Report LA-12503-MS, 1993.

57. Yokota, H., et al "A New Concept for Low Emission Diesel Combustion”, SAE Paper 970891, 1997.

58. Akagawa, H., et al "Approaches to Solve Problems of the Premixed Lean Diesel Combustion", SAE Paper 1999-01-183, 1999.

59. Lund, C. M., "HCT - A General Computer Program for Calculating Time Dependent Phenomena Involving One-Dimensional Chemical Kinetics", Lawrence Livermore National Laboratory Report UCRL-52504, 1978.

60. Kee, R.J., et al "CHEMKIN: A Fortran Chemical Kinetics Package for the Analysis of Gas-Phase Chemical and Plasma Kinetics", Sandia National Laboratories Report SAND 96-8216, 1996.

61. Woschini, G. "Universally Applicable Equation for the Instantaneous Heat Transfer Coefficient in the Internal Combustion Engine", SAE Paper 670931, 1967.

62. Smith, J.R., et al "Modelling of Homogenous Charge Compression Ignition (HCCI) of Methane, ASME Internal Combustion Engine Conference, Wisconsin, USA, 1997.

63. Aceves, S.M., et al "Compression Ratio Effect on Methane HCCI Combustion", ASME Journal of Engineering for Gas Turbines and Power, Vol.21, 1999.

64. Kraft, M., et al "Investigation of Combustion Emissions in HCCI Engine-Measurements and a New Computational Model", $28^{\text {th }}$ International Combustion Symposium, Edinburgh, 2000. 